\title{
The Thermal Response of Aircraft Cabin Ceiling Materials during a Post-Crash, External Fuel-Spill, Fire Scenario
}

\author{
LEONARD Y. COOPER \\ Center for Fire Research \\ National Bureau of Standards \\ Gaithersburg, Maryland 20899, USA
}

\section{AB S TRACT}

An algorithm is developed to predict the thermal response of aircraft ceiling materials during a post-crash fire scenario. The scenario involves an aircraft's emergency exit doorway which opens onto the flames of a fuel-spill fire which engulfs the fuselage. Data of near-ceiling temperatures acquired during fu11scale, post-crash test simulations provide indirect validation of the algorithm. The post-crash time-to-ceiling-ignition is proposed as a measure of cabin fire safety. This measure would be used as a surrogate for the post-crash time avai1able for passengers to safely evacuate the cabin. In this sense, the algorithm is exercised in an example evaluation of the fire safety of a candidate honeycomb ceiling material used together in cabin systems involving polyurethane cushion seating.

\section{INTRODUCTION}

The purpose of this investigation is to analyze aircraft cabin ceiling surface temperature data recently acquired during full-scale test simulations of postcrash fires. The analysis is carried out with a view toward the development of a procedure for estimating the temperature histories of overhead aircraft cabin materials subsequent to the ignition of exterior, fuel-spil1 fires. With such a capability it would be possible to estimate the time for such materials to reach ignition temperatures. This would result in a rational means of ranking the fire safety of candidate overhead aircraft cabin materials.

Al1 tests described here were carried out by the U.S. Department of Transportation Federal Aviation Administration (FAA), Atlantic City, New Jersey.

\section{DESCRIPTION OF THE TESTS}

The experiments simulated a wide-body aircraft cabin post-crash fire, similar to those reported previous $1 y^{l}$. The scenario involved a fuselage with two open doorways where one of these is engulfed by an external fuel spil1 fire. The fire is simulated by a burning $2.44 \mathrm{~m} \times 3.05 \mathrm{~m}$ pan of jet fuel (JP-4). The threat to the cabin by this test fire has been shownl to be representative of the threat by real, external fue1-spill fires. No-wind conditions were simulated. The test article was a surplus U.S. Air Force Cl33A cargo alrcraft.

The celling of the test cabin was made up of 0.0127 m thick rigid Kaowool ${ }^{\circledR}$ ceramic fiber board, where $\mathrm{k}=0.045 \mathrm{~W} / \mathrm{mK} ; \alpha=2.67\left(10^{-7}\right) \mathrm{m}^{2} / \mathrm{s}$. A mockup seat made of cushions on a steel frame was placed in the cabin in front of the open doorway exposed to the fire. The study involved eight tests. The only parameter which 
varied from test to test was the seat cushion construction. Test 111 is designated as the background test since it involved the seat frame with no cushioning. Data from Test 111 were available for $240 \mathrm{~s}$ after ignition. Data from all other tests were only avallable for $120 \mathrm{~s}$. A schematic of the test setup is presented in Fig. 1.

During the tests, the radiant heat flux near the doorway, and $0.30 \mathrm{~m}$ and $0.91 \mathrm{~m}$ above the floor, was measured with fluxmeters facing outward toward the fire. Throughout each test, and from one test to another these two fluxes were substantially similar. It will be assumed that this flux, qürad-door, is uniform and isotropic across the entire doorway, and that it can be approximated by the lower flux measured in Test 111 (see Fig. 2).

This study considers near-ceiling temperatures measured by three thermocouples placed in the line traversing the width of the cabin, and directly above the center of the doorway as shown in Fig. 1. The thermocouples were of 24 gage (0.000584 $\mathrm{m}$ diameter) chromel/alumel wire. The wire was supported several centimeters from its bead, and there was an attempt to position the bead close to

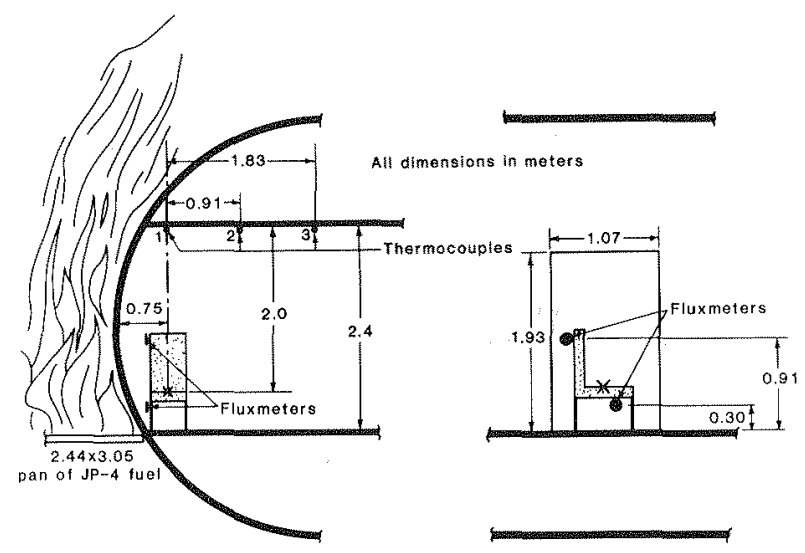

FIGURE 1. A schematic of the test setup.

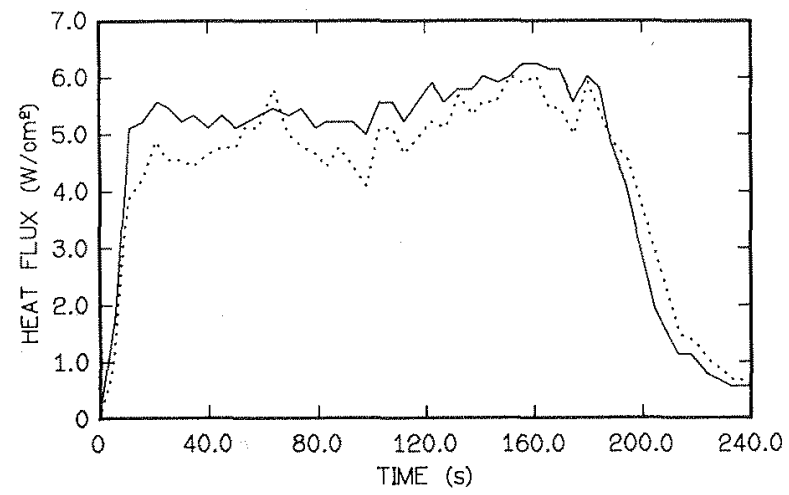

EIGURE 2. Measured doorway heat flux vs time (lower fluxmeter....; upper fluxmeter —); test 111 (background). 
the ceiling surface so that the bead temperatures would be substantially similar to the nearby, celling temperatures. The bead-to-ceiling distances were probably of the order of $0.001 \mathrm{~m}$.

Up to $120 \mathrm{~s}$ after ignition, the measured temperatures at each of the three positions and for all eight tests were substantially similar2. It is, therefore, reasonable to assume that, for the threat scenario being simulated and up to the $120 \mathrm{~s}$, fire development in a single, mockup seat would not add significantly to the celling surface fire threat. Thus, it is assumed to be adequate to study the thermal response of the ceiling only during Test 111. Plots of the measured near-ceiling thermocouple temperatures during this test are presented in Fig. 3.

\section{AN ANALYSIS OF THE THERMAL RESPONSE OF THE CABIN CEILING MATERIAL}

Two major phenomena can lead to relatively prompt lower surface heating of the cabin ceiling. The first involves the thick flames and copious products of combustion which engulf the exterior of the fuselage near the exposed, open, doorway. These lead to radiative and convective heat flux to the cabin ceiling.

The convection is from the hot, buoyant gases of the fire which are captured by the open doorway. Upon entering the cabin, these gases are driven upward toward the ceiling, forming an outward (i.e., away from the doorway and toward the cabin interior) moving ceiling jet. After spreading radially from the doorway, this ceiling jet is redirected away from the general location of the doorway and toward the front and rear of the cabin. Eventually the hot, captured, products of combustion start to fill the cabin. They then participate in venting from the second open doorway and in complicated entrainment processes which develop at the fire-exposed, open doorway itself. An analysis of the external fire and the captured flow under rather general wind conditions has been presented previous ly ${ }^{3}$.

The second phenomenon leading to ceiling heating involves the fire which spreads in the seating. Here, the single-seat scenario of the present tests results in only marginally important levels of celling heat flux. Yet, fire spread in a fully outfitted cabin could lead to a significant additional threat to the cabin ceiling. The seating fire leads to both radiative and convective heating of the ceiling. The radiation would be primarily from the fire's combustion zone, and the convection from the fire's plume-driven ceiling jet. This ceiling jet would augment the previously mentioned, captured-gas-driven celling jet.

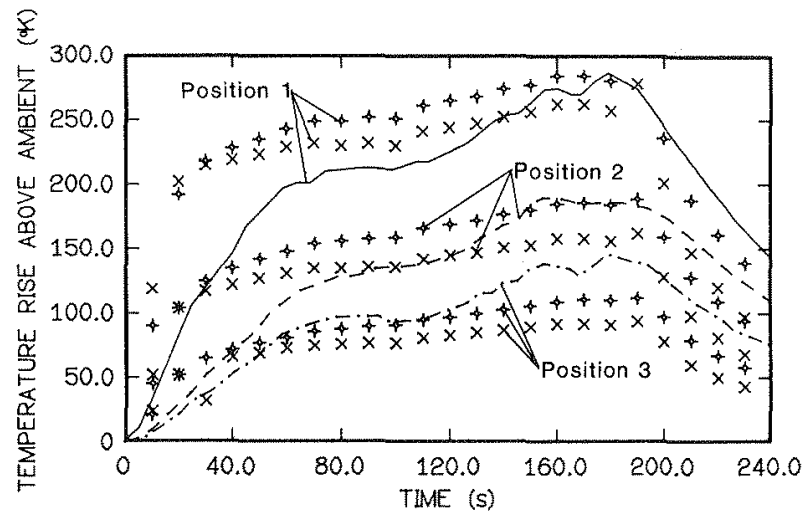

FIGURE 3. Computed Test 111 ceiling temperature $\left(+: \beta=0 ; x: \beta=3.0 \mathrm{~m}^{2}\right)$, and corresponding measured near-ceiling temperatures at positions 1,2 , and 3 . 
other components of heat flux to/from both the upper and lower ceiling surfaces are radiation from relatively cool, far-field surfaces and reradiation from the ceiling surfaces themselves. In an analysis of the ceiling heating it 1s reasonable to account for natural convection cooling of the ceiling's upper surface, and to adopt the relatively simple geometry of Fig. 4. Estimates for the components of ceiling heat transfer are developed below. Using these, the problem for the thermal response of the ceiling is then formulated and solved.

\section{Radiation from Doorway to Ceiling}

The radiant flux through the door, and to the ceiling is taken to be

$\dot{q}_{\text {door-ceiling }}=\dot{q}_{\text {rad-door }}{ }^{\mathrm{F}} \mathrm{A}-\mathrm{dA}$

where $\mathrm{F}_{\mathrm{A}-\mathrm{dA}}$ is the viewfactor ${ }^{4}$ given in Fig. 5 .

Captured External Fire Product Gases - An Equivalent Buoyant Source

The "captured gas" doorway plume is modeled by a nonradiating, equivalent, point source of buoyancy located at the center of the horizontal surface of the mockup seat (see Fig. 4). The strength of the equivalent source, Qequiv, is assumed to be directly proportional to qrad-door* Thus

$\dot{Q}_{\text {equiv }}=\beta \dot{q}_{\text {rad-door }}^{\prime \prime}\left(\beta\right.$ in $\left.\mathrm{m}^{2}\right)$

Radiation and Convection for the Seating Fire

During the first $120 \mathrm{~s}$ of the fire, celling heat transfer from the burning single mockup cabin seat was not significant. However, in fully outfitted cabins, it is anticipated that this situation would be changed, especially after the first minute or two subsequent to ignition. By these times, fires in multiple-seat configurations have been observed to grow and spread beyond single seat involvement. Since the present analysis will be extended to fully outfitted cabin scenarios, ceiling heat transfer contributions from the seating fire will be included at the outset.

The seating fire is simulated by a time-dependent point source of energy release rate, $\dot{Q}_{\text {seat, }}$ assumed to be located with the nonradiating source, $\dot{Q}_{\text {equiv, at the }}$ center of the horizontal surface of the outer, exposed, doorway seat. A fraction, $\lambda_{\mathrm{r}}$ seat, of $\mathrm{Q}_{\text {seat }}$ is assumed to be radiated unfformly over a sphere to the far fleld. The remaining energy release rate, $\left(1-\lambda_{r}\right.$, seat $) Q_{\text {seat }}$, drives the buoyant fire plume upward. Thus, the radiation from the seating fire to the celling is assumed to be

$\dot{q}_{\text {rad-seat }}^{*}=\lambda_{\text {r, seat }} \dot{Q}_{\text {seat }} /\left[4 \pi \mathrm{H}^{2}\left(1+\mathrm{r}^{2} / \mathrm{H}^{2}\right)^{3 / 2}\right]$

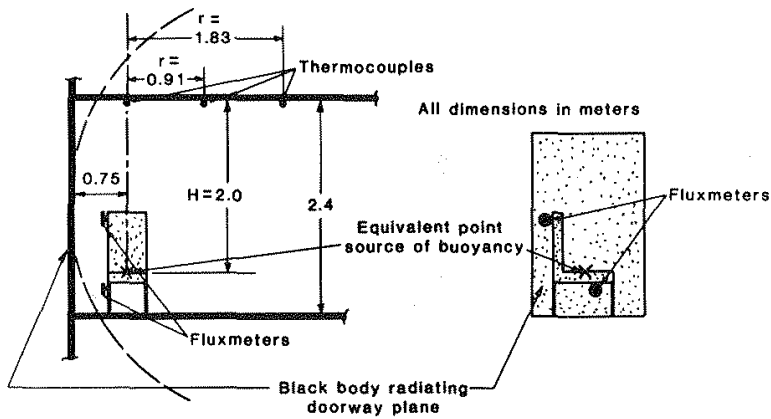

FIGURE 4. A simplified version of the post-crash fire scenario. 


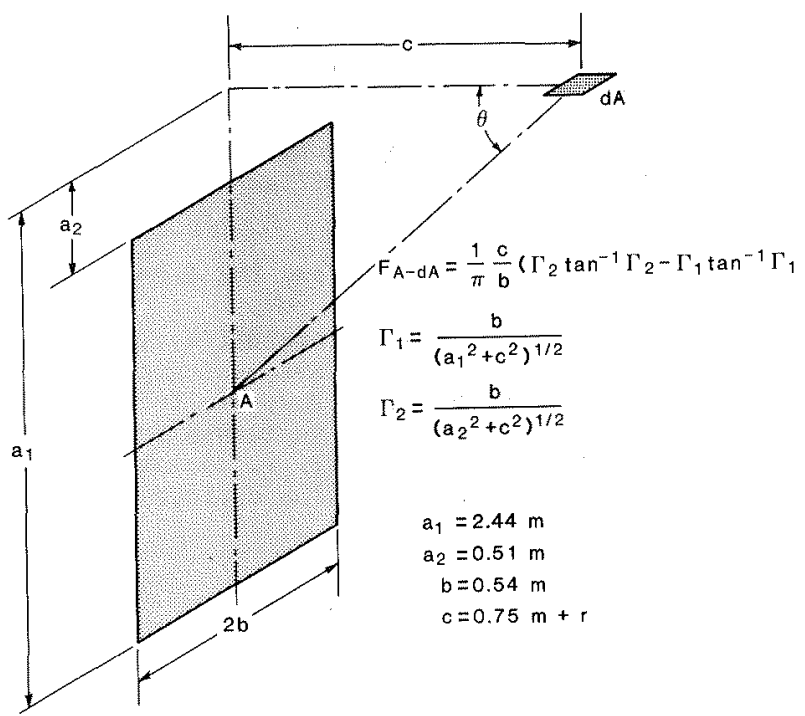

FIGURE 5. The viewfactor between the doorway and a ceiling element.

$\dot{Q}_{\text {seat }}$ would vary from one seat cushion construction to another. $\dot{Q}_{\text {seat }}$ would typically have to be estimated from test data, and then specified in the present analysis. $\lambda_{r}$, seat would also vary somewhat from one construction to another, although it is reasonable to choose the value 0.35 , a value which characterizes the radiation from flaming combustion zones of many practical fuel assemblies ${ }^{5}$. This value is adopted here.

Convective Heat Transfer from a Combined, Equivalent Source of Buoyancy

$Q$, is the combined enthalpy flux of the upward moving combustion gases. Thus $\dot{Q}=\dot{Q}_{\text {equiv }}+\left(1-\lambda_{\text {r, seat }}\right) \dot{Q}_{\text {seat }}$

A11 convective heat transfer to the cabin celling is from the 0 -generated, plumedriven, celling jet, and is estimated by 6,7

$\dot{\mathrm{q}}_{\text {conv, }}^{\prime \prime}=\mathrm{h}_{\mathrm{L}}\left(\mathrm{T}_{\mathrm{ad}}-\mathrm{T}_{\mathrm{S}, \mathrm{L}}\right)$

$\frac{\left(\mathrm{T}_{\mathrm{ad}}-\mathrm{T}_{\mathrm{amb}}\right)}{\mathrm{T}_{\mathrm{amb}} \dot{\mathrm{Q}}^{* 2 / 3}}=\left\{\begin{array}{l}10.22 \exp (-1.77 \mathrm{r} / \mathrm{H}), 0 \leq \mathrm{r} / \mathrm{H} \leq 0.75 \\ 2.10(\mathrm{r} / \mathrm{H})^{-0.88}, 0.75 \leq \mathrm{r} / \mathrm{H}\end{array}\right.$

$h_{L} / \tilde{h}=\left\{\begin{array}{l}7.75 \operatorname{Re}^{-0.5}\left[1-\left(5.0-0.390 \operatorname{Re}^{0.2}\right)(\mathrm{r} / \mathrm{H})\right], 0 \leq \mathrm{r} / \mathrm{H} \leq 0.2 \\ 0.213 \operatorname{Re}^{-0.3}(\mathrm{r} / \mathrm{H})^{-0.65}, 0.2 \leq \mathrm{r} / \mathrm{H} \leq 1.03 \\ 0.217 \operatorname{Re}^{-0.3}(\mathrm{r} / \mathrm{H})^{-1.2}, 1.03 \leq \mathrm{r} / \mathrm{H}\end{array}\right.$

$Q^{*}=\dot{Q} /\left(\rho_{a m b} C_{p} T_{a m b} g^{1 / 2} H^{3 / 2}\right) ; \tilde{h}=\rho_{a m b} C_{p} g^{1 / 2} H^{1 / 2} q^{*}{ }^{1 / 3} ; R e=g^{1 / 2} H^{3 / 2} Q^{*} 1 / 3 / \nu$ 
The above algorithm is for heat transfer to unconfined ceilings. In using it here, two major assumptions are made; namely, effects of the upper smoke layer are relatively weak during the early times of interest, and the interactions of the ceiling jet and lateral cabin wall surfaces, especially surfaces immediate to the doorway side of the plume-ceiling impingement point, will not lead to total heat transfer flux amplitudes which are significantly larger than peak values that will be estimated with their neglect.

Radiation Between the Lower Celling Surface and the Far-Field Cabin Surfaces

The lower cefling surface is assumed to radiate diffusely to the illuminated surfaces of the cabin and its furnishings. Responding to this, the temperatures of those surfaces also increase with time. However, for times of interest here, it is assumed that these latter temperature increases are always relatively $s$ ma11. compared to the characteristic increases of $\mathrm{T}_{\mathrm{S}, L^{*}}$ Accordingly, the net radiation exchange between the ceiling and the nonburning surfaces below can be approximated by

$\dot{\mathrm{q}}_{\text {rerad, } \mathrm{L}}=\varepsilon_{\mathrm{L}}$ o( $\left.\mathrm{T}_{\mathrm{S}, \mathrm{L}}^{4}-\mathrm{T}_{\mathrm{amb}}^{4}\right)$

Heat Transfer from the Upper Ceiling Surface

Heat is transferred through the ceiling, and eventually the temperature of its upper surface, which is also assumed to be exposed to a constant $\mathrm{T}_{\text {amb }}$ environment, begins to rise. Heat transfer from this surface has convective and radiative components. These are estimated by

$\dot{\mathrm{q}}{ }_{\text {conv }, U}=\mathrm{h}_{\mathrm{U}}\left(\mathrm{T}_{\mathrm{s}, \mathrm{U}}{ }^{-\mathrm{T}} \mathrm{amb}\right) ; \dot{\mathrm{q}}_{\text {rerad }, \mathrm{U}}^{*}=\varepsilon_{\mathrm{U}} \sigma\left(\mathrm{T}_{\mathrm{s}, \mathrm{U}}^{4}-\mathrm{T}_{\mathrm{amb}}^{4}\right)$

where $^{8} \quad \mathrm{~h}_{\mathrm{U}}=1.675\left|\mathrm{~T}_{\mathrm{s}, \mathrm{U}}-\mathrm{T}_{\mathrm{amb}}\right|^{1 / 3} \mathrm{~W} / \mathrm{m}^{2}(\mathrm{~T}$ in $\mathrm{K})$

The Boundary Value Problem for the Ceiling, and the Method of Its Solution

The temperature field of the celling is assumed to be governed by the Fourler heat conduction equation. Initially, the ceiling is at temperature, $\mathrm{T}_{\mathrm{amb}}$. The rates of heat transfer to the lower and upper surfaces, are

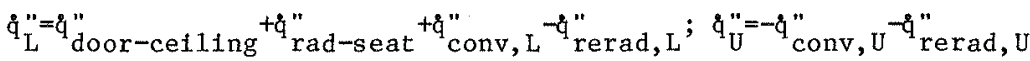

Radial gradients of varlables of the problem are assumed to be small. enough so that conduction in the celling is quasi-one dimensional in space. An illustration of the idealized, fire scenario is presented in Fig. 6.
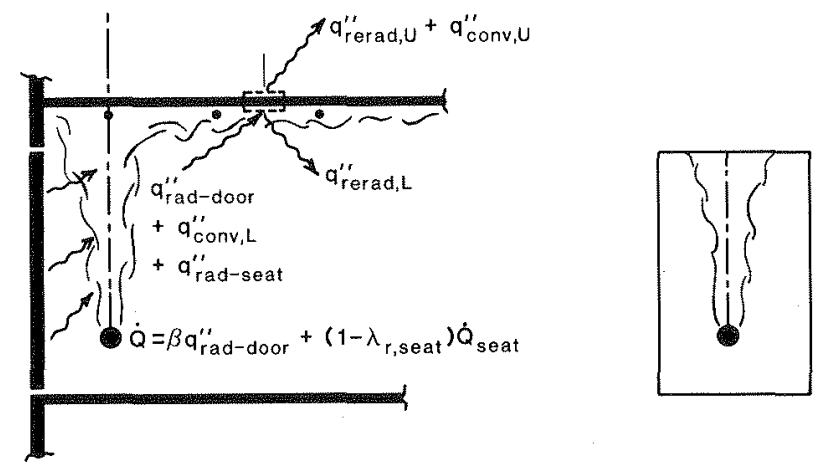

FIGURE 6. The idealized post-crash fire scenario. 
A computer program for solving the above problem was developed. The solution to the heat conduction equation for the celling at every radial position of interest is by finite differences 10,11 . For a given calculation, $\mathrm{N}<20$ equally spaced points are positioned at the surfaces and through the thickness of the ceiling. The spacing of these, $\delta Z$, is selected to be large enough to insure stability of the calculation. The change in time for all time steps is made small enough so that, at a given lower surface node, the temperature increases from time step to time step never exceed one percent of the current value of $T$.

\section{CALCULATION OF THE RESPONSE OF THE CEILING IN THE POST-CRASH TEST SIMULATION}

The algorithm was used to predict the response of the Kaowool ${ }^{10}$ ceiling during the first $240 \mathrm{~s}$ of Test 111 . Here and in the next section all surfaces are assumed to radiate and absorb as black bodies. Qseat was taken to zero, and $\dot{q}^{\prime \prime}$ ad-door as identical to the Test 111, underseat flux measurement. Ceiling temperatures at positions 1, 2 and 3 were computed for different $\beta^{\prime} \mathrm{s}$ in the range $0 \leq \beta \leq 6.0 \mathrm{~m}^{2}$. (This range of $\beta$ leads to the approximate Qequiv range $0 \leq$ Qequiv $\leq 300 \mathrm{~kW}$.) The computed lower ceiling histories for $\beta=0$, and $3.0 \mathrm{~m}^{2}$ are plotted in Fig. 3 .

The Importance of $\dot{Q}$ equiv

If convective ceiling heating from dooway-captured products of combustion is equivalent to that from a seat fire of the order of a few hundred $\mathrm{kW}$, then the calculated results plotted in Fig. 3 indicate that such heating is not significant compared to doorway radiation. (Except for the very earliest few seconds, convection from the relatively weak source associated with $\beta=3.0 \mathrm{~m}^{2}$ is seen to lead to net cooling of the strongly irradiated ceiling surface.) This result is consistent with earlier observations where variations in single seat cushion construction (peak energy release rates likely never exceeding the few hundred $\mathrm{kW}$ level) did not lead to significant differences in near-celling temperatures.

\section{Comparisons Between Computed and Measured Temperatures}

Per Fig. 3 the peak computed values of celling temperature compare favorably with the corresponding peak temperatures measured by the near-ceiling thermocouples. However, the basic qualitative characteristics of the computed and measured transient thermal responses are significanlty different. Namely, the measured temperatures do not have the same type of rapid response which the solution properly predicts for the ceiling surface temperatures. Also, the close tracking of the position 2 and 3 thermocouples at early times does not compare favorably with a like tracking of the computed temperatures.

Two conclusions result from these observations: the thermocouples are not at the temperature of the celling surface, and, therefore, data to validate the analysis are not evident. As a result of these conclusions, an analysis of the response of the thermocouples was carried out in order to explain the measured thermocouple responses, and with the hope of obtaining a measure of experimental validation, albelt indirect, for the predicted ceiling response.

\section{AN ANALYSIS OF THE THERMAI RESPONSE OF THE NEAR-CEILING THERMOCOUPLES}

The objective of the present analysis is to predict the thermal response of the thermocouples when placed near, but not touching the ceiling. The procedure for positioning these devices prior to testing was such that the thermocouple wires were essentially parallel to the lower celling surface and at a distance, d, of the order of $0.001 \mathrm{~m}$. The actual orientation of the wire relative to the doorway plane is unknown. As depicted in Fig. 7, the analysis will consider two extreme configurations for the wire, viz., normal and parallel to the doorway. 


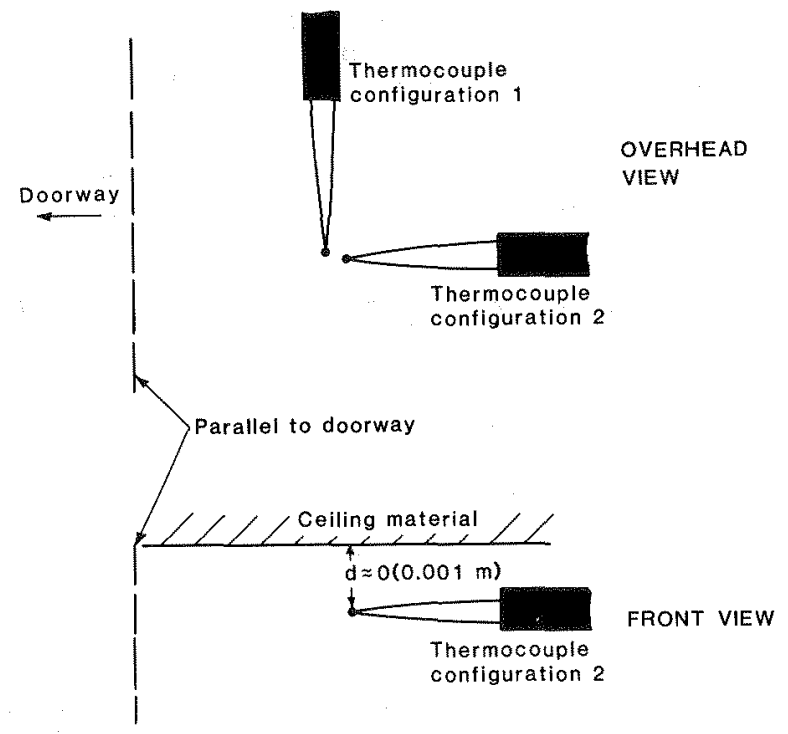

FIGURE 7. Two extreme configurations for placement of the near-ceiling the rmocouples.

The characteristic time for conductive heat transfer through the wire thickness is of the order of tenths of a second. It will therefore be assumed that the wire is spatially uniform in temperature. Properties of the chromel/alumel wire will be taken as those of Nicke 1, viz., $\rho=8800 \mathrm{~kg} / \mathrm{m}^{3}, \mathrm{C}_{\mathrm{p}}=460 \mathrm{Ws} /(\mathrm{kgK})$.

From the literature5,11,12 it is estimated that the thickness of the ceiling jet within which the thermocouples are submerged are of the order of several centimeters. With a characteristic d, of the order of $0.001 \mathrm{~m}$, it is therefore reasonable to assume that gas velocities local to the thermocouple wire are so small that forced convection vs radiative heating of the wire is negligible. Also, the characteristic Grashof numbers would be relatively sma11, and any natural convection would be reduced to a conduction limit. This would be dependent on the unknown distance $d$.

At early times radiation from the doorway drives the temperature increase of the thermocouple. Also, a steady-state analysis which balances doorway heating and radiation exchanges between thermocouple, ceiling and ambient (i.e., which ignores conduction) leads to a result which is consistent with late-time, Fig. 3 , measured and computed temperatures of thermocouple and ceiling, respectively.

The thermal analysis which emerges from the above discussion leads to the following equation for the temperature, $\mathrm{T}_{w}$, of the thermocouple wire

$\frac{\pi}{4} \rho C_{p} D^{2} \frac{d T}{d t}=Q_{\text {door-wire }}^{\prime}+Q_{\text {ceiling-wire }}^{\prime}+Q_{\text {amb-wire }}^{\prime}{ }^{-Q_{\text {wire }}^{\prime}}$

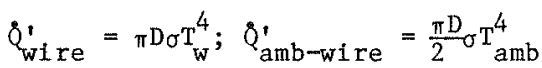

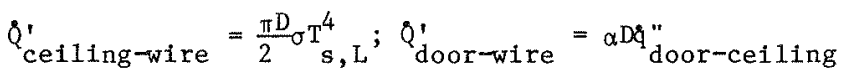


$\alpha=\{1$ for configuration 2 of Fig. 7

\{1/sine (see Fig. 5) for configuration 1 of Fig. 7

To obtain $T_{\mathrm{W}}$ one would specify $\alpha$ and $\mathrm{T}_{\mathrm{S}}, \mathrm{L}$, use the measured values of $\dot{\mathrm{q}}$ rad-door to obtain qudoor-ceiling, and solve Eq. (13) subject to $T_{W}(t=0)=T_{a m b}$.

Solutions for $T_{w}$ in the Test 111 Scenario

The above procedure was applied to the Test 111 scenario. The analysis was carried out numerically for a thermocouple in position 1,2 or 3 and in configuration 1 or 2 . In each case, $\mathrm{T}_{\mathrm{S}, \mathrm{L}}$ was taken from the celling temperature calculations described earlier.

$T_{w}$ calculations were carried out for $\beta$ values of $2.0 \mathrm{~m}^{2}, 3.0 \mathrm{~m}^{2}$, and $4.0 \mathrm{~m}^{2}$. $\beta=3.0 \mathrm{~m}^{2}$ results are presented in Fig. 8 , which includes the measured $T_{w}$ of Fig. 3 .

Comparison Between Computed and Measured Temperatures - A Choice for $\beta$

Perhaps of greatest significance in Fig. 8 is the early-time thermocouple temperature predictions, which were of particular concern in the ceiling vs thermocouple temperature comparisons of Fig. 3. Here, the simulations of the early, near-linear responses of the thermocouples are noteworthy.

Of further significance is the fact that the calculations reveal a possible explanation for the close tracking of the response of the thermocouples at positions 2 and 3. Namely, such behavior is predicted if the thermocouple wire at position 2 was normal to the door plane (configuration 2), and the thermocouple wire at position 3 was parallel to the door plane (configuration 1).

Fig. 8-type plots provide a basis for selecting the "best" value for $\beta$. The $\beta$ predicting a ceiling response which, in turn, yields the most favorable comparisons between calculated and measured values of $\mathrm{T}_{\mathrm{w}}$ would be the obvious choice. Calculations reveal that the $T_{w}$ predictions are not very sensitive to $\beta$ variations in the approprtate range $2.0-4.0 \mathrm{~m}^{2}$. Furthermore, of the values $\beta=2.0 \mathrm{~m}^{2}$, $3.0 \mathrm{~m}^{2}$, and $4.0 \mathrm{~m}^{2}$, all yielded reasonable $\mathrm{T}_{\mathrm{w}}$ predictions, and no one of these values clearly yields more favorable $\mathrm{T}_{\mathrm{w}}$ predictions than the others. $\beta=3.0 \mathrm{~m}^{2}$ w111 be chosen as the "best" value.

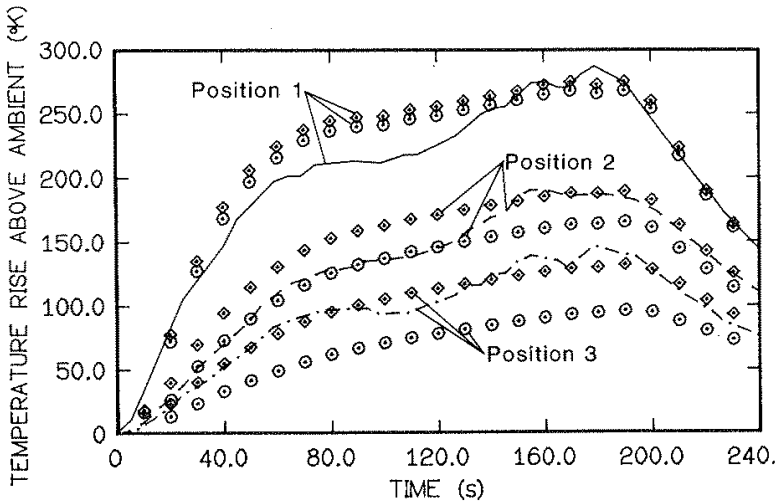

FIGURE 8. Predicted and measured test 111 thermocouple temperatures $\left(\beta=3.0 \mathrm{~m}^{2}\right)$. $\langle\bullet\rangle$ : Predicted $\mathrm{T}_{\mathrm{W}}$, configuration $1 ; 0$ : Predicted $\mathrm{T}_{\mathrm{W}}$, configuration 2 ; : Measured $\mathrm{T}_{\mathrm{W}}$ 
The above results provide some confidence in the ceiling thermal response algorithm. To use it to simulate the post-crash fire exposure in a fully-seated cabin, effects of fire spread in an array of seating must be included. This would be done by inputing appropriate, nonzero, $\lambda_{r}$, seat and $Q_{\text {seat }}$ terms in Eqns. (3) and (4). Then, using the $k$ and $\alpha$ of a candidate ceiling material, the algorithm would calculate the celling's time-dependent, post-crash, thermal response.

In the most likely case of a combustible ceiling material, one could, for example, predict the time for the lower surface to reach a characteristic ignition temperature. Results of a previous FAA program indicate that away from the combustion zone tenable conditions are maintained throughout the cabin prior to celling ignition. The time-to-celing ignition would therefore provide a reasonable measure of post-crash cabin fire safety, viz., the minimum time available for passengers to evacuate the cabin or the Available Safe Egress Time (ASET) 13. Hopefully, evaluations of practical cabin ceiling material candidates would lead to assocfated ignition times, or minimum ASET's, which exceed the time required for cabin evacuation. In any event, the greater the time-to-ignition of a material the better.

In the case of a noncombustible ceiling, time-to-ignition in the above discussion would be replaced by time to reach some agreed upon ceiling temperature, e.g., $600^{\circ} \mathrm{C}$, which is often associated with cabin flashover.

\section{Estimates of Post-Crash Fire Growth in Arrays of Cabin Seats - An Example}

Estimates of the energy release rate of post-crash fires spreading through arrays of seats were obtained previously14. Based on FAA, ful1-scale, 21 seat tests which were similar to Tests 104-111, estimates of fire growth in two types of seat construction were obtained. The first type of seats, designated as "regular" seats, were made of fire retarded polyurethane foam covered with wool-nylon fabric. The second seat construction was similar to the first, except that it included a blocking layer constructed of a $0.0048 \mathrm{~m}$ thick sheet of neoprene with a polyester scrim.

The estimates of $\dot{Q}_{\text {seat }}$ for the two types of seats are plotted in Fig. 9. The plots terminate at $140 \mathrm{~s}$ and $185 \mathrm{~s}$, at which times video-tape recordings of the tests indicated the initiation of either flashover (140 s) or of rapid development of total obscuration $(185 \mathrm{~s})$. These estimates will be used below to evaluate the post-crash response of a specific, honeycomb ceiling material.

\section{POST-CRASH RESPONSE OF A HONEYCOMB CEILING MATERIAL - ESTIMATES OF TIME-TO-IGNITION}

The algorithm developed here was used to estimate the post-crash thermal response of a $0.0254 \mathrm{~m}$ thick, honeycomb composite, aircraft ifning material with an epoxy fiberite covering. The effective thermal properties of the composite were measured, and found to bel $\mathrm{k}^{5}=5.9\left(10^{-5}\right) \mathrm{kW} /(\mathrm{mK}) ; \rho=110 . \mathrm{kg} / \mathrm{m}^{3} ; \alpha=4.8\left(10^{-7}\right) \mathrm{m}^{2} / \mathrm{s}$; $\mathrm{C}_{\mathrm{p}}=1.11 \mathrm{~kJ} /(\mathrm{kgK})$. Qseat was simulated by the plots of Fig. 9 .

The predicted temperature of the celling above the doorway seat is plotted in Fig. 10 for both "regular" seating and "blocked" seating. The ignition temperature of the honeycomb material had been measured previously, and was found to be $16536^{\circ} \mathrm{C}$. Thus, results of $\mathrm{Fig}$. 10 predict onset of celling ignition at 148 and $204 \mathrm{~s}$ for "regular" and "blocked" seating, respectively. For cabin ceilings of this honeycomb material, blocked rather than unblocked seating would lead to a $56 \mathrm{~s}$ advantage in ASET. 


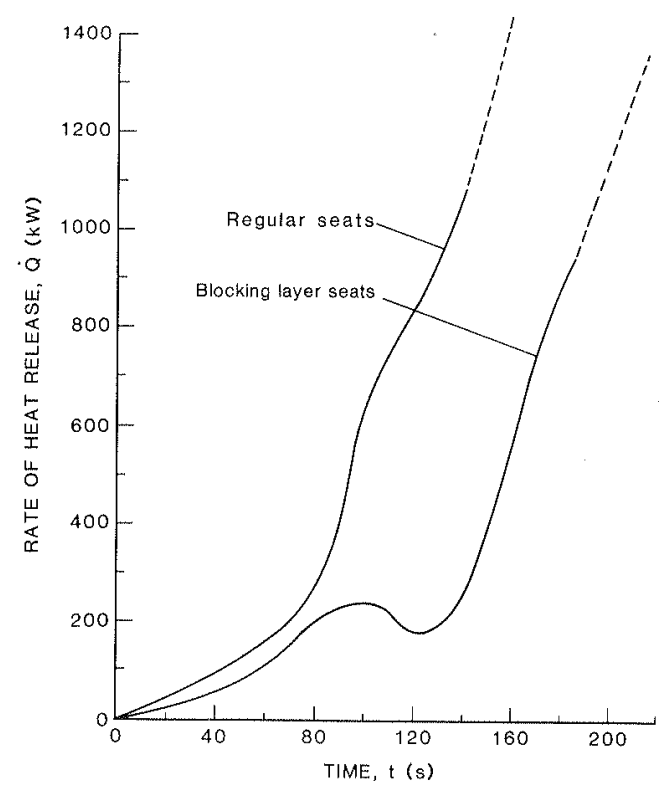

FIGURE 9. Estimate for $Q_{\text {seat }}$ for arrays of polyurethane seats with and without blocking layers [13] extrapolated from curves of [13]).

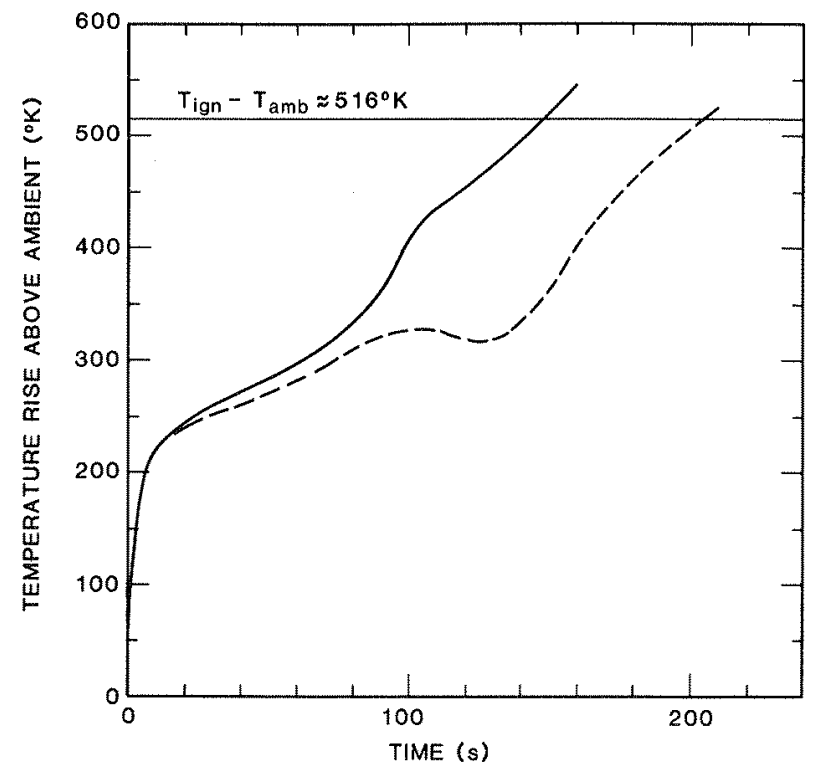

FIGURE 10. Predicated temperature of the honeycomb ceiling material in a cabin with polyurethane seats: with and without blocking layers. 


\section{REFERENCES}

1. Hi11, R.G., Johnson, G.R. and Sarkos, C.P., Postcrash Fuel Fire Hazard Measurements in a Wide-Body Aircraft Cabin, FAA-NA-79-42, Fed. Aviation Admin., Atlantic City, NJ, 1979.

2. Cooper, L.Y., The Thermal Response of Aircraft Cabin Ceiling Materials During a Post-Crash External Fue1-Spi11 Fire Scenar1o, NBSIR 84-2912, Nat. Bur. of Stand. Gatthersburg, MD, 1984.

3. Emmons, H.W., The Ingestion of Flames and Fire Gases Into a Hole in an Aircraft Cabin for Arbitrary Tilt Angles and Wind Speed, Home Fire Proj. Rpt. 52, Harvard UnIv. Div. App1. Sciences, Cambridge, MA, 1982.

4. Eckert, E.R.G. and Drake, R.M., Heat and Mass Transfer, McGraw-Hi11, 1959.

5. Cooper, L.Y., A Mathematical Model for Estimating Available Safe Egress Time in Fires, Fire and Mat., 6, p. 135, 1982.

6. Cooper, L.Y., Heat Transfer from a Buoyant Plume to an Unconfined Ceiling, J. Heat Trans., 104, p. 446, 1982.

7. Cooper, L.Y., Thermal Response of Unconfined Ceilings Above Growing Fires and the Importance of Convective Heat Transfer, 22nd Nat'1. Heat Transfer Conf., ASME Paper 84-HT-105, 1984 and NBSIR 84-2856, Nat. Bur. Stand., Gaithersburg, MD, 1984.

8. Yousef, W.W., Tarasuk, J.D. and McKeen, W.J., Free Convection Heat Transfer from Upward-Facing, Isotherma1, Horizontal Surfaces, J. Heat Trans., 104, p. 493,1982 .

9. Emmons, H.W., The Prediction of Fires in Bulldings, 17th Symp. (Inter,) on Combustion, p. $1101,1979$.

10. Mitler, H.E. and Emmons, H.W., Documentation for the Fifth Harvard Computer Fire Code, Home Fire Proj. Rpt. 45, Harvard Unjv., Cambridge, MA, 1981.

11. Poreh, M., Tsuei, Y.G. and Cermak, J.E., Investigation of a Turbulent Radial Wa11 Jet, ASME J. of App1. Mech., p. 457, 1967.

12. Alpert, R.L., Turbulent Ceiling-Jet Induced by Large-Scale Fires, Comb. Sci. and Tech., Vol. 11, p. 197, 1975.

13. Cooper, L.Y., A Concept of Estimating Safe Available Egress Time, Fire Safety Journa1, Vo1. 5, p. 135, 1983.

14. Steckler, K., Chapter 1: The Role of Aircraft Pane1 Materials in Cabin Fire and Their Properties, DOT-FAA CT 84/30, Nat. Bur. Stand. rpt. to Fed. Aviation Admin., Atlantic City, NJ, 1985.

15. Parker, W., Nationa1 Bureau of Standards, private communication.

16. Harkleroad, M., Quintiere, J. and Walton, W., Radiative Ignition and Opposed Flame Spread Measurements on Materials, DOT/FAA/CT-83/28 (Nat. Bur. Stand. rpt: to Fed. Aviation Admin., Atlantic City, NJ, 1983. 


\section{NOMENCLATURE}

$a_{1}, a_{2}, b, c$

dimensions, Fig. 5

$\mathrm{C}_{\mathrm{p}}$

$\mathrm{D}$

d

$\mathrm{F}_{\mathrm{A}-\mathrm{dA}}$

$\mathrm{g}$

H

$h_{\mathrm{L}}, h_{U}$

$\tilde{\mathrm{n}}$

$k$

$\mathrm{N}$

Q, Q*

Qequiv' $Q_{\text {seat }}$
$Q_{\text {amb-wire, Q }}^{\prime}$ ceiling-wire

Q'door-wire, Q'

q" conv, U, q" conv, $\mathrm{L}$

q" door-ceiling

$\dot{q}$ rad-door' $\dot{q}_{\text {rad-seat }}^{\prime \prime}$

$\dot{q}_{\text {rerad, }}^{\prime \prime}$, q" "rerad, L

specific heat

wire diameter

the rmocouple-to-ceiling separation distance

view factor, Eq. (1), Fig. 5

acceleration of gravity

seat fire-to-celling distance

lower/upper surface heat transfer coefficient

characteristic heat transfer coefficient, Eq. (8)

thermal conductivity

number of grid points in ceiling analysis

enthalpy flux in plume, Eq. (4), dimensionless $\dot{Q}$, Eq. (8)

equivalent fire strength, strength of seat fire

radiation: ambient to wire, ceiling to wire per unit

length

radiation: doorway to wire, from wire per unit length

convection to upper/lower ceiling

radiation from doorway to ceiling

radiation from doorway, from seat fire to celling

radiation from upper/lower celling

net heat transfer to upper/lower ceiling

Reynold's number, Eq. (8)

distance from plume impingement point

adiabatic celling temperature, Eq. (6); ambient

temperature

upper/lower surface ceiling temperature

thermocouple wire temperature

time

Indepth ceiling coordinate

thermal diffusivity/wire configuration constant, Eq. (15)

a constant

constants, Fig. 5

indepth spacing of ceiling grid points

lower/upper ceiling emissivity

configuration angle, Fig. 5

fraction of $Q_{\text {seat }}$ radiated

kinematic viscosity of ambient air

density, density of ambient

Stefan-Boltzmann constant 
